\title{
DNA Mimics Containing Non-Nucleosidic Base Surrogates
}

\author{
Simon M. Langenegger, Gapian Bianké, Rolf Tona, and Robert Häner*
}

\begin{abstract}
Chemically modified nucleic acids find widespread use as tools in research, as diagnostic reagents and as pharmaceutical compounds. While the major efforts in the past concentrated on the generation of sugar-based nucleotide analogues, the potential of non-nucleosidic and non-hydrogen bonding building blocks is largely untouched to date. Such derivatives may have an impact in the fields of materials and genetic research. In this paper, some recent findings of our work in this area are highlighted.
\end{abstract}

Keywords: DNA · Hairpin · Mimic · Oligonucleotides · Stacking

\section{Introduction}

The fast growth and development currently observed in the field of nucleic acids chemistry can be attributed to three major developments. The first area comprises the use of short nucleic acids as highly specific agents which allow the direct and highly selective interference with the flow of genetic information. Both antisense [1-4] and antigene [5][6] oligonucleotides, as well as short interfering RNAs (siRNAs) [7] are widely used for this purpose. The success of these approaches is founded, to a significant extent, on the high reliability and predictability of the base-pairing scheme according to Watson and Crick [8]. The second area, which can largely be described as the field of genetic diagnostics, includes the use of oligonucleotides and analogous derivatives as genetic probes. Tools such as oligonucleotide microarrays or molecular beacons play an important role in life science research. Again, the success of this field is largely founded on the high specificity of

${ }^{\star}$ Correspondence: Prof. Dr. R. Häner

Department of Chemistry and Biochemistry

University of Bern

Freiestrasse 3

$\mathrm{CH}-3012$ Bern

Tel.: +41316314382

E-Mail: robert.haener@ioc.unibe.ch

http://www.dcb.unibe.ch/groups/haener the base pairing scheme. The third area, which is currently emerging as a focus of interest, consists in the use of nucleic acids as frameworks for the construction of molecular architectures [9-12]. There is today a considerable and growing interest in the use of nucleic acids for the assembly of molecular structures on the nanometre scale. Among the properties which render nucleic acids the object of primary interest for this purpose are the following: i) the ability of self-organisation; ii) their chemical and physical stability; iii) they are amenable to a large variety of chemical, physical and biological manipulations; iv) modified building blocks can be readily incorporated; and v) they can be predictably assembled in a modular way for the construction of oneto three-dimensional structures. As in the two previously mentioned areas, the predictability of the base pairing is again the most important aspect. A few simple rules allow the precise planning of the annealing of complementary strands. In combination with the repetitive, well-defined and wellpredictable structural features of nucleic acids, this renders them valuable building blocks for the generation of nanometersized molecular structures [13]. In addition, the structural variety of 'nucleic acids' can be substantially increased by alteration of the building blocks as impressively demonstrated by the work of Eschenmoser [14]. New types of monomeric units will very likely lead to novel structures and, hence, novel functions of the oligomers composed of them. While the major efforts in the past concentrated on the generation of sugarbased nucleotide analogues, the potential of non-nucleosidic and non-hydrogen bonding building blocks is largely untouched to date. Here, we will give a short overview on our research aimed at the design and synthesis of DNA mimics containing such types of base surrogates.

\section{Non-Nucleosidic Building Blocks with Interstrand Stacking Properties}

Over the last few years, we have started to explore the synthesis and properties of nucleic acids containing various novel types of non-nucleosidic, non-hydrogen bonding monomers. As a first example, the phenanthrene and phenanthroline building blocks $\mathbf{P}$, shown in Fig. 1, were synthesized and incorporated into oligonucleotides [15][16].

Hybrids containing pairs of such building blocks in opposing positions form a coherent, continuous duplex rather than segmented stretches of duplex DNA interrupted by the polyaromatic residue. This is remarkable, since the linkers have no similarity to the sugar moiety of 'normal' nucleosides. Apparently, the lack of preorganisation introduced by the flexible linkers does not prevent the formation of a B-DNA like duplex. The model shown in Fig. 1, which was derived on the basis of different experimental results, suggests a duplex with the polyaromatic moieties arranged in an interstrand stacking mode. A related polyaromatic building block is the pyrene derivative Pyr shown in Fig. 2A. Like the analogous phenanthroline and phenanthrene, this building block gives rise to stable hybrids. It is, thus, possible to arrange aromatic moieties in a well-defined arrangement into close (stacking) contact. In a way, the surrounding nucleic acids can 

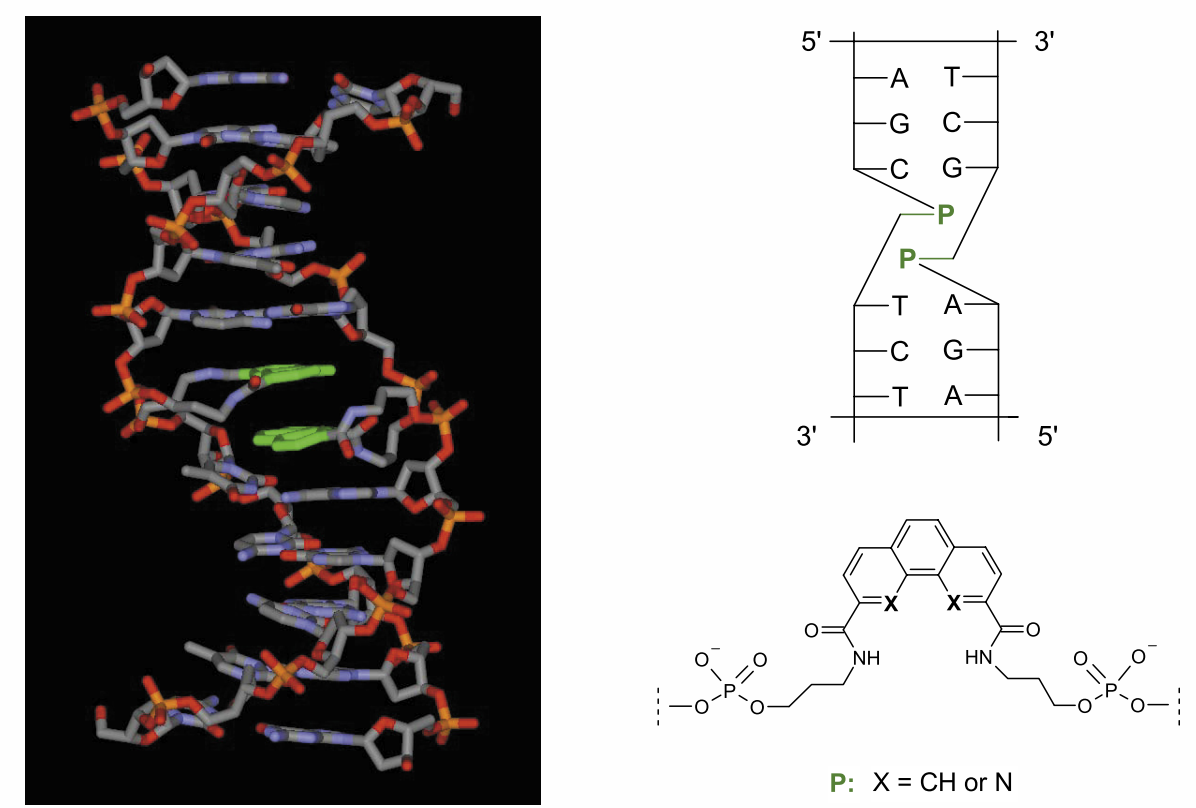

P: $\mathrm{X}=\mathrm{CH}$ or $\mathrm{N}$

Fig. 1. Illustration of a modified DNA duplex showing two non-nucleosidic, polyaromatic building blocks (green) in an interstrand stacking arrangement

A

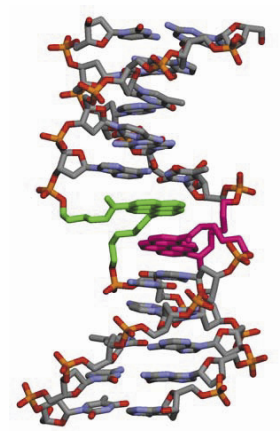

B

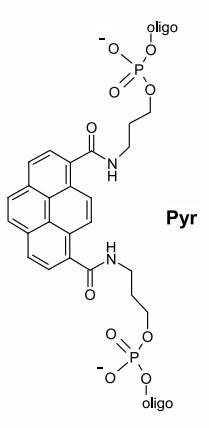

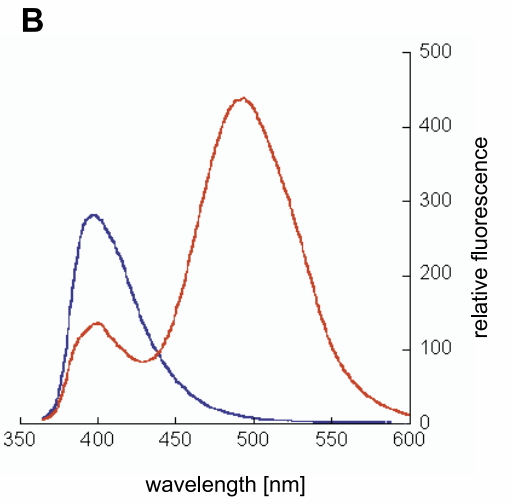

Fig. 2. (A) Molecular model showing a DNA duplex with two interstrand stacked pyrenes (view perpendicular to the helical axis); the non-nucleosidic building blocks are highlighted in red and green. (B) Fluorescence emission spectra of a single strand (blue) and duplex (red) containing nonnucleosidic pyrenes in opposite positions. The emission band at approx. $500 \mathrm{~nm}$ is due to formation of an excimer by the two interstrand stacked pyrenes.
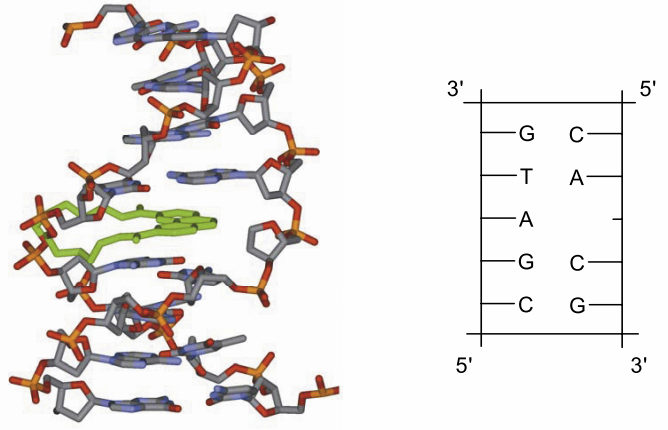

stabilization
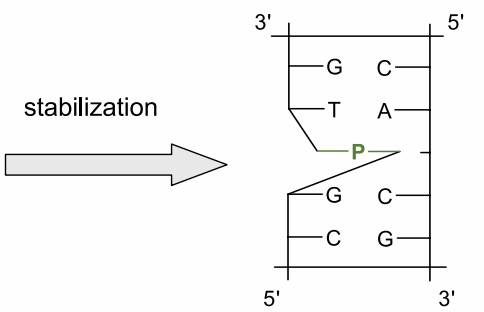

Fig. 3. Amber-minimized structure of a DNA duplex containing a non-nucleosidic polyaromatic building block (highlighted in green) opposite to an abasic site be regarded as a framework to bring the compounds into close proximity. While this is not unique - modified nucleotides [13] and other types of monomers [17] are being used as templates for this and related purposes - the present approach allows the placement of any number of non-nucleosidic building blocks in fixed positions within the core of the DNA in a rather simple way. Alternatives include the use of non-hydrogen bonding 'nucleobases' in conjunction with a regular nucleoside backbone [1820]. The synthesis of such building blocks is, however, rather lengthy and demanding in general. Simplicity may well prove to be an advantage in later practical applications. Such practical applications include the generation of specific signals, which are induced by the proximity of two or more components. Pyrene for example is well known to form an excimer upon irradiation of two monomers, which are in close contact [21]. The spectrophysical consequence of excimer formation is the appearance of fluorescence emission with a significant (up to $100 \mathrm{~nm}$ ) bathochromic shift compared to fluorescence of the monomer. This is indeed observed for the duplex in which the two pyrenes are interstrand stacked (Fig. 2B) [22].

\section{Structural Stabilization of Abasic Sites in DNA}

The use of phenanthrene and phenanthroline modified oligonucleotides was further extended to the structural stabilization of DNA containing an abasic site. Abasic sites represent a common type of lesion in DNA. If not repaired, they can lead to mutations during replication or to cell death. Due to its biological importance, there is a strong interest in methods of recognizing abasic sites in DNA both, for diagnostic and also for potential pharmaceutical applications. Intercalating ligands [23][24] have been evaluated as inhibitors of enzymatic repair processes to increase the efficacy of cytotoxic agents [25]. Due to the remarkable stacking properties, we addressed the question whether the non-nucleosidic building block could be used to 'fill' the cavity, which is generated upon loss of a base in DNA. Indeed, we observed an increase of several degrees in Tm upon placement of a phenanthrene $\left(+5.7^{\circ} \mathrm{C}\right)$, a pyrene $\left(+6.9^{\circ} \mathrm{C}\right)$ or a phenanthroline $\left(+8.9^{\circ} \mathrm{C}\right)$ opposite to an abasic site (Fig. 3) [26][27].

Significant work aimed at the recognition or stabilisation of abasic sites in duplex DNA using complementary oligonucleotides carrying modified nucleosides has also been reported by Kool and coworkers [28][29]. They showed that placement of extended aromatic residues opposite to the abasic site can substitute for the miss- 

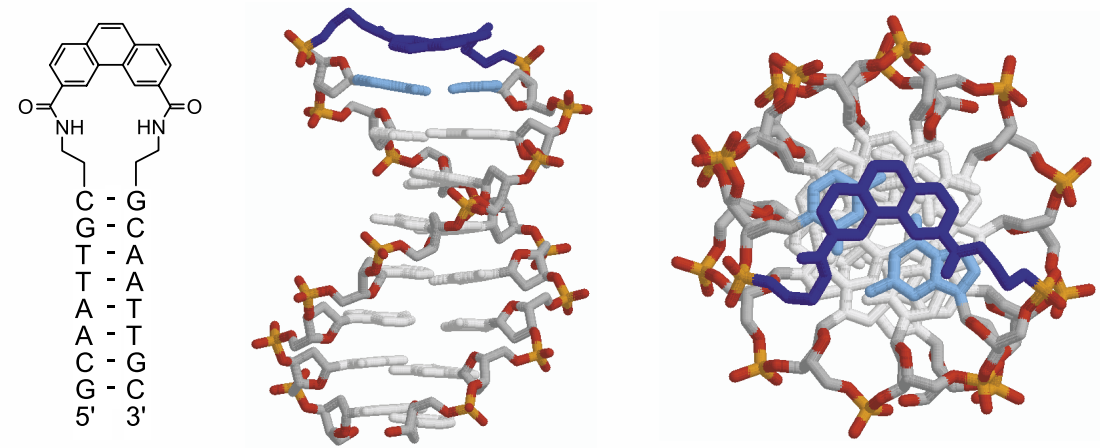

Fig. 4. Amber-minimized structures of a DNA hairpin mimic containing a phenanthrene loop (dark blue). The view is shown perpendicular to (middle) and along (left) the helical axis. The base pair adjacent to the phenanthrene is shown in light blue.

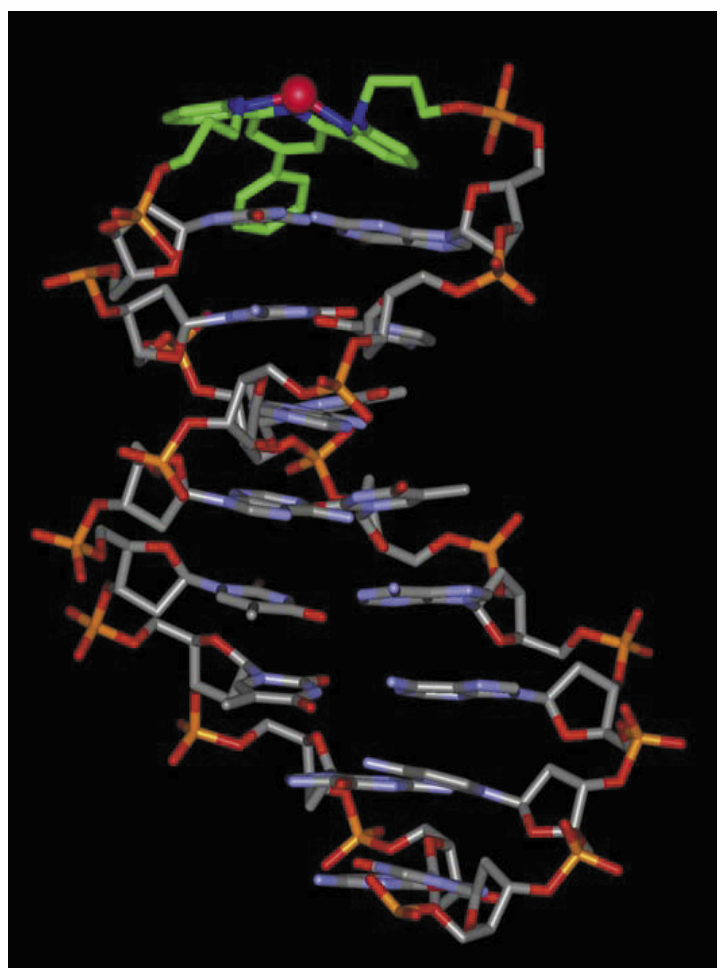

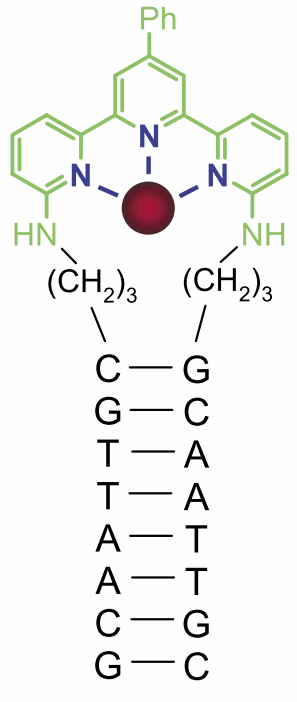

$5^{\prime}$

$$
=\mathrm{M}^{2+}
$$

Fig. 5. Model of a DNA hairpin mimic containing a terpyridine moiety (green; nitrogens are shown in blue) with a bound $\mathrm{Cu}^{2+}$-ion (red sphere).

ing nucleobase and maintain the aromatic stacking throughout the duplex. Deoxyribofuranosides carrying pyrene and other polyaromatic hydrocarbons have been used for this purpose. Most of the reported surrogates are deoxyribose-derived, a fact that originates from the goal of leaving the sugar-phosphate backbone as little changed as possible, compared to the natural DNA backbone [30]. In an elegant approach, Wagenknecht and coworkers [31] recently reported the detection of abasic sites using a non-nucleosidic phenanthridium building block.

\section{Hairpin Mimics}

A second part of our research is aimed at the generation and investigation of hairpin mimics. As in the area of peptide mimics, mimicries of secondary structural motifs of nucleic acids are synthesized and investigated. Such analogues may find use as tools in research or even as RNA-targeting oligonucleotide analogues (e.g. as loop-modified antisense [32] or shRNAs, short hairpin RNAs [33]). We found that phenanthrene can function as an excellent replacement of the hairpin loop. Self-complementary oli- gonucleotides containing a phenanthrene in the middle of the sequence form hairpinlike secondary structures, which are considerably more stable than the natural counterpart (Fig. 4) [34].

In addition to the 'structural' loop replacement (the phenanthrene), we also pursued the synthesis and investigation of 'functional' hairpin mimics. Thus, a metal coordinating hairpin mimic was prepared, which contained a terpyridine derived unit as loop replacement. It was shown that the structural stability of the hairpin is dependent on the presence of transition metals, as well as by the type of the coordinated metal (Fig. 5) [35].

The generation and investigation of hairpin mimics has also been pursued by other groups. Thus, the hairpin loop has been replaced with flexible oligoethylene glycol linkers [36-38] as well as with more rigid aromatic derivatives [39-41] and metal complexes [42][43]. Most prominently, Letsinger and Lewis have investigated trans-stilbene hairpin analogues, some of which possess a very high structural stability [39][40].

Most recently, the functionality of the hairpin mimics was extended to a loop possessing chemical reactivity. A selfcomplementary oligonucleotide containing a 1,3-diene derived linker also forms a stable secondary structure. Furthermore, such hairpin mimics undergo Diels-Alder reactions with substituted maleimides and can, thus, be functionalized with a variety of different substituents (illustrated in Fig. 6) $[44][45]$.

\section{Conclusions}

New types of non-nucleosidic, non-hydrogen bonding building blocks have been synthesised, which can easily be incorporated into oligonucleotides. Despite their structural simplicity, these building blocks function as nucleotide surrogates. They allow the formation of stable hybrids by interstrand stacking interactions between the aromatic moieties and they can be used for the stabilization of abasic sites in DNA. The use of pyrene derivatives leads to strong excimer formation in both single as well as double strands. Furthermore, several types of non-nucleosidic building blocks have been used for the construction of hairpin mimics.

\section{Acknowledgements}

We thank all current and former members of the group for their valuable contributions. Financial support of our research in this area by the Swiss National Foundation is gratefully acknowledged. 

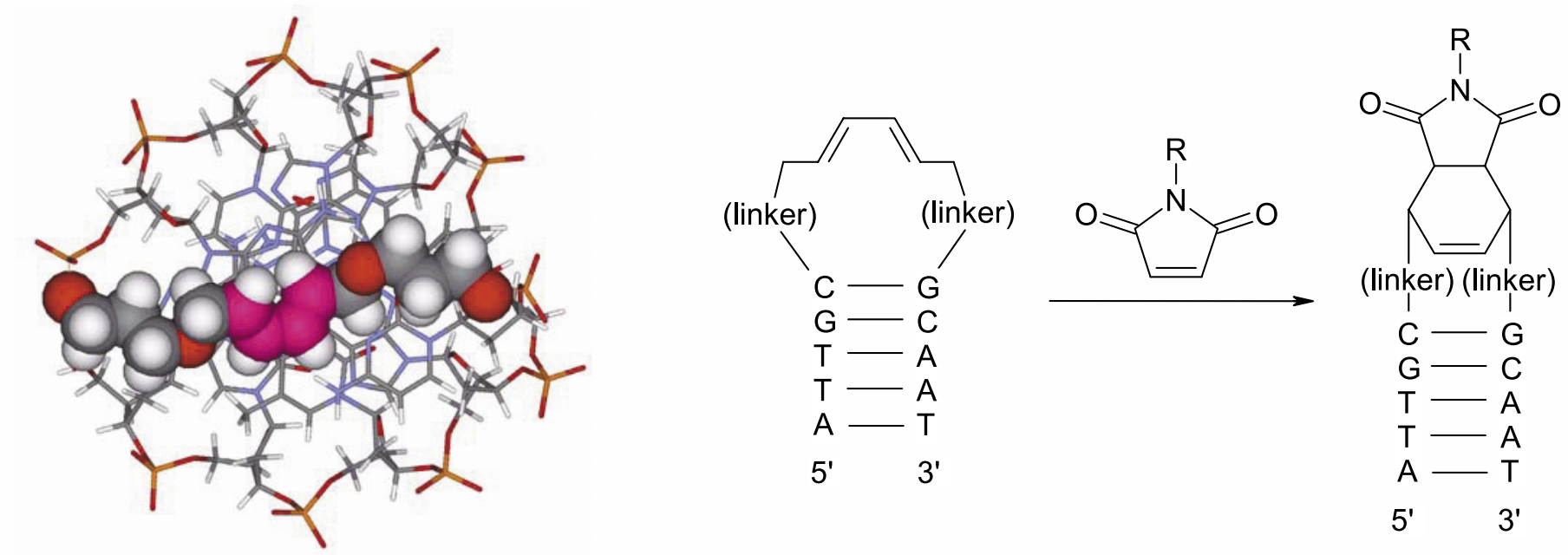

Fig. 6. Right: Molecular model of a 1,3-diene derived DNA hairpin mimic (view along the helical axis). The synthetic linker is displayed in a space filling representation and the butadiene moiety (highlighted in red) is shown in the s-cis conformation. Left: Bioconjugation of the 1,3-diene-based hairpin mimic via Diels-Alder reactions with $\mathrm{N}$-substituted maleimides.

Received: August 17, 2005

[1] C. Hélène, J.J. Toulmé, Biochim. Biophys. Acta 1990, 1049, 99-125.

[2] E. Uhlmann, A. Peymann, Chem. Rev 1990, 90, 543-584.

[3] A. De Mesmaeker, R. Häner, P. Martin, H.E. Moser, Acc. Chem. Res. 1995, 28, 366-374.

[4] S.T. Crooke, Annu. Rev. Med. 2004, 55, 61-95.

[5] K.R. Fox, Curr. Med. Chem. 2000, 7, 1737.

[6] S. Buchini, C.J. Leumann, Curr. Opin. Chem. Biol. 2003, 7, 717-726.

[7] J. Hall, Nature Reviews Genetics 2004, 5 , 552-557.

[8] J.D. Watson, F.H.C. Crick, Nature 1953, 171,737-738.

[9] N.C. Seeman, Nature 2003, 421, 427431.

[10] R. Bashir, Superlattices and Microstructures 2001, 29, 1-16.

[11] W.M. Shih, J.D. Quispe, G.F. Joyce, $\mathrm{Na}$ ture 2004, 427, 618-621.

[12] C.A. Mirkin, Inorg. Chem. 2000, 39, 2258-2272.

[13] J. Wengel, Org. Biomol. Chem. 2004, 2, 277-280.

[14] A. Eschenmoser, Science 1999, 284, 2118-2124.

[15] S.M. Langenegger, R. Häner, Helv. Chim. Acta 2002, 85, 3414-3421.

[16] S.M. Langenegger, R. Häner, Tetrahedron Lett. 2004, 45, 9273-9276.

[17] C.B. Nielsen, M. Petersen, E.B. Pedersen, P.E. Hansen, U.B. Christensen, Bioconjug. Chem. 2004, 15, 260-269.

[18] E.T. Kool, Acc. Chem. Res. 2002, 35, 936943.

[19] G. Mathis, J. Hunziker, Angew. Chem. Int. Ed. 2002, 41, 3203-3205.

[20] C. Brotschi, G. Mathis, C.J. Leumann, Chemistry-A European Journal 2005, 11, 1911-1923.
[21] F.M. Winnik, Chem. Rev. 1993, 93, 587614.

[22] S.M. Langenegger, R. Häner, Chem. Commun. 2004, 2792-2793.

[23] N. Berthet, J.F. Constant, M. Demeunynck, P. Michon, J. Lhomme, J. Med. Chem. 1997, 40, 3346-3352.

[24] K. Yoshimoto, S. Nishizawa, M. Minagawa, N. Teramae, J. Am. Chem. Soc. 2003 , 125, 8982-8983.

[25] J. Lhomme, J.F. Constant, M. Demeunynck, Biopolymers 1999, 52, 65-83.

[26] S.M. Langenegger, R. Häner, Chem. Biodiv. 2004, 1, 259-264.

[27] S.M. Langenegger, R. Häner, ChemBioChem 2005, 6, 848-851.

[28] S. Smirnov, T.J. Matray, E.T. Kool, C. los Santos, Nucleic Acids Res. 2002, 30 , 5561-5569.

[29] T.J. Matray, E.T. Kool, Nature 1999, 399, 704-708.

[30] E.T. Kool, J.C. Morales, K.M. Guckian, Angew. Chem. Int. Ed. 2000, 39, 9901009.

[31] L. Valis, N. Amann, H.A. Wagenknecht, Org. Biomol. Chem. 2005, 3, 36-38.

[32] S.J. Kim, E.K. Bang, H.J. Kwon, J.S Shim, B.H. Kim, ChemBioChem 2004, 5 , 1517-1522.

[33] D. Siolas, C. Lerner, J. Burchard, W. Ge, P.S. Linsley, P.J. Paddison, G.J. Hannon, M.A. Cleary, Nat. Biotechnol. 2005, 23 , 227-231.

[34] A. Stutz, S.M. Langenegger, R. Häner, Helv. Chim. Acta 2003, 86, 3156-3163.

[35] G. Bianké, R. Häner, ChemBioChem 2004 5, 1063-1068.

[36] M. Durand, K. Chevrie, M. Chassignol, N.T. Thuong, J.C. Maurizot, Nucleic Acids Res. 1990, 18, 6353-6359.

[37] M.Y.X. Ma, L.S. Reid, S.C. Climie, W.C. Lin, R. Kuperman, M. Sumnersmith, R.W. Barnett, Biochemistry 1993, 32, 1751-1758.
[38] W. Pils, R. Micura, Nucleic Acids Res. 2000, 28, 1859-1863

[39] M. Salunkhe, T.F. Wu, R.L. Letsinger, $J$. Am. Chem. Soc. 1992, 114, 8768-8772.

[40] F.D. Lewis, R.S. Kalgutkar, Y.S. Wu, X.Y. Liu, J.Q. Liu, R.T. Hayes, S.E. Miller, M.R. Wasielewski, J. Am. Chem. Soc. 2000, 122, 12346-12351.

[41] K. Yamana, A. Yoshikawa, H. Nakano, Te trahedron Lett. 1996, 37, 637-640.

[42] F.D. Lewis, S.A. Helvoigt, R.L. Letsinger, Chem. Commun. 1999, 327-328.

[43] J.L. Czlapinski, T.L. Sheppard, ChemBioChem 2004, 5, 127-129.

[44] R. Tona, R. Häner, Chem. Commun. 2004, 1908-1909.

[45] R. Tona, R. Häner, Bioconjug. Chem 2005, 837-842. 